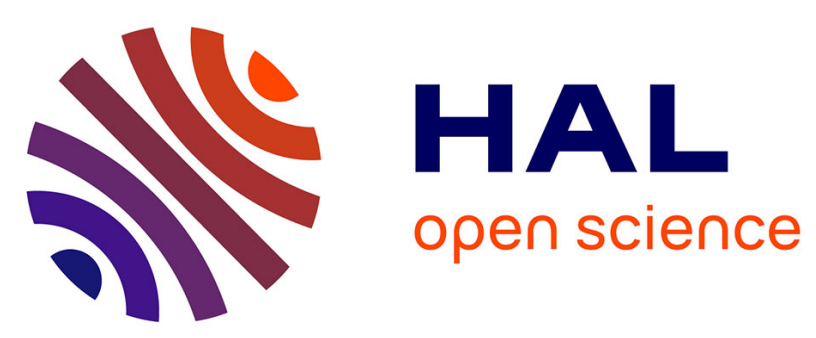

\title{
Bioimpedance analysis is safe in patients with implanted cardiac electronic devices
}

Xavier Chabin, Ouarda Taghli-Lamallem, Aurélien Mulliez, Pierre Bordachar, Frédéric Jean, Emmanuel Futier, Grégoire Massoullié, Marius Andonache, Géraud Souteyrand, Sylvain Ploux, et al.

\section{To cite this version:}

Xavier Chabin, Ouarda Taghli-Lamallem, Aurélien Mulliez, Pierre Bordachar, Frédéric Jean, et al.. Bioimpedance analysis is safe in patients with implanted cardiac electronic devices. Clinical Nutrition, 2019, 38, pp.806 - 811. 10.1016/j.clnu.2018.02.029 . hal-03486695

\section{HAL Id: hal-03486695 https://hal.science/hal-03486695}

Submitted on 20 Dec 2021

HAL is a multi-disciplinary open access archive for the deposit and dissemination of scientific research documents, whether they are published or not. The documents may come from teaching and research institutions in France or abroad, or from public or private research centers.
L'archive ouverte pluridisciplinaire HAL, est destinée au dépôt et à la diffusion de documents scientifiques de niveau recherche, publiés ou non, émanant des établissements d'enseignement et de recherche français ou étrangers, des laboratoires publics ou privés.

\section{다)(1) $(5$}

Distributed under a Creative Commons Attribution - NonCommerciall 4.0 International 


\section{BIOIMPEDANCE ANALYSIS IS SAFE IN PATIENTS WITH IMPLANTED}

\section{CARDIAC ELECTRONIC DEVICES}

1 Xavier Chabin ${ }^{a}$ MD; Ouarda Taghli-Lamallem ${ }^{a}$ PhD; Aurélien Mulliez ${ }^{b}$ MSc; Pierre Bordachar ${ }^{c}$ MD,

$2 \mathrm{PhD}$; Frédéric Jean ${ }^{\mathrm{a}} \mathrm{MD}$; Emmanuel Futier ${ }^{\mathrm{d}} \mathrm{MD}, \mathrm{PhD}$; Grégoire Massoullié ${ }^{\mathrm{a}} \mathrm{MD}$; Marius Andonache ${ }^{\mathrm{a}}$

3 MD, PhD; Géraud Souteyrand ${ }^{1}$ MD; Sylvain Ploux ${ }^{3}$ MD, PhD; Yves Boirie ${ }^{5}$ MD, PhD; Ruddy

4 Richard $^{\mathrm{e}} \mathrm{MD}, \mathrm{PhD}$; Bernard Citron ${ }^{\mathrm{a}} \mathrm{MD}, \mathrm{PhD}$; Jean-R Lusson ${ }^{\mathrm{a}} \mathrm{MD}, \mathrm{PhD}$; Thomas $\operatorname{Godet}^{\mathrm{d}} \mathrm{MD}, \mathrm{PhD}$;

5 Bruno Pereira ${ }^{\mathrm{b}} \mathrm{PhD}$; Pascal Motreff ${ }^{\mathrm{a}} \mathrm{MD}$, PhD; Guillaume Clerfond ${ }^{\mathrm{a}}$ MD; Romain Eschalier ${ }^{\mathrm{a}}$ MD,

$6 \mathrm{PhD}$.

\footnotetext{
a Université Clermont Auvergne, Cardio Vascular Interventional Therapy and Imaging (CaVITI), Image Science for Interventional Techniques (ISIT), UMR6284, and CHU Clermont-Ferrand, Cardiology Department, F-63003 ClermontFerrand, France.

${ }^{\mathrm{b}}$ CHU Clermont-Ferrand, Biostatistics unit (Clinical Research and Innovation Direction), F-63000 Clermont-Ferrand, France.

${ }^{\mathrm{c}}$ Hôpital Cardiologique du Haut-Lévêque, CHU Bordeaux, Université Bordeaux, IHU LIRYC, Bordeaux, France.

${ }^{\mathrm{d}}$ Department of Perioperative Medicine, Anesthesiology and Critical Care Medicine, Estaing Hospital, University Hospital of Clermont-Ferrand and CNRS, Inserm U1103, GreD, Clermont-Ferrand, France.

${ }^{\mathrm{e}}$ Nutrition Department, CHU Clermont-Ferrand, F-63003 Clermont-Ferrand, France.
}

ADDRESS FOR CORRESPONDENCE: Romain Eschalier, Cardiology Department, Rue Montalembert, 63000 Clermont-Ferrand, France.

Tel: +33473751410 ; Fax: +33473754730; e-mail: reschalier@chu-clermontferrand.fr

This work was performed without any financial support.

Trial registered under the identifier NCT03045822.

Word Count: 4760 


\section{Abstract}

8 Background and Aims. There are an increase in the number of patients worldwide with

9 cardiac implantable electronic devices (CIEDs). Current medical practice guidelines warn 10 against performing bioimpedance analysis (BIA) in this group of patients in order to avoid 11 any electromagnetic interference. These recommendations restrict using the BIA in patients 12 undergoing heart failure or with nutrition disorders in whom BIA could be of major interest in 13 detecting peripheral congestion and to help guide treatment. The present study was conducted 14 to evaluate whether BIA caused electromagnetic interference in patients having CIEDs.

15 Methods. Patient enrollment was conducted during routine face-to-face consultations for 16 scheduled CIEDs interrogations. Device battery voltage, lead impedance, pacing thresholds 17 and device electrograms were recorded before and after each BIA measurement to detect any 18 electromagnetic interference or oversensing.

19 Results. A total of 200 patients were enrolled. During BIA, no significant changes in battery 20 voltage, lead impedance or pacing thresholds were detected, nor were there any inappropriate 21 over- or undersensing observed in intracardiac electrograms. Furthermore, 6- and 12-month 22 follow-up did not reveal any changes in CIEDs.

23 Conclusions. This study shows no interference in patients equipped with CIEDs and suggests 24 that BIA can be securely performed in these patients.

25 Keywords: Bioimpedance analysis, pacemakers, implantable cardioverter-defibrillator, 26 device interference 


\section{INTRODUCTION}

28 Current medical guidelines have prompted the implantation of an increasing number of 29 cardiac implantable electronic devices (CIEDs) such as pacemakers (PM) and implantable 30 cardioverter defibrillators (ICDs) [1]. A large survey in 2009 revealed worldwide 31 implantation of 300000 ICDs and over 1 million of PM [2]. These CIEDs rely on complex 32 microcircuitry and are susceptible to interact with electromagnetic interference produced by 33 medical equipment such as magnetic resonance imaging, electrosurgery and bioelectrical 34 impedance [3]'[4].

35 Bioimpedance analysis (BIA) has been highly valued for its noninvasiveness, safety, low cost, 36 ease of use and is widely used for measurements of the body composition [5]'[6]. BIA 37 methodology allows the assessment of fat-free mass (FFM) and total body water (TBW). The 38 analysis of body composition by BIA has gained increasing recognition in numerous 39 biomedical applications, including nutrition, hemodialysis for the estimation of hydration 40 state and sports medicine [7], [8], [9]',[10]. It is also applied in disease diagnosis such as late41 stage lung cancer and pulmonary edema, as well as in gastrointestinal and cardiovascular 42 diseases[11]'[12]'[13]'[14]'[15]. In particular, thoracic BIA has been applied for diagnostic, therapeutic and prognostic purposes in patients with heart failure, those waiting for heart transplantation and patients with hypertension[14]'[16]'[17].

While it is poorly acknowledged that BIA actually interferes with CIEDs function, guidelines and manufacturers recommend not performing BIA in patients with CIEDs, since it may cause inappropriate shocks or pacing inhibition (Nutriguard-MS: instructions for use. http://www.data-input.de/media/pdf_english_2014/instructions-for-use-nutriguard-ms.pdf. Accessed May $\left.5^{\text {th }}, 2017\right)$, [6]. These recommendations restrict performing BIA in many patients with cardiovascular diseases. Therfore, the present study aimed to assess whether 
51 BIA caused electromagnetic interference in patients with CIEDs during a BIA test, including

52 over a follow-up of 12 months.

53

54

55

56

57

58

59

60

61

62

63

64

65

66

67

68

69

70

71

72

73

74

75

76

METHODS

\section{Study population}

In this prospective study, patients were enrolled during routine face-to-face follow-up consultations for scheduled for PM and ICD interrogations. The study was reviewed and approved by the local ethics committee (Approval Reference: AU1069) and the National Security Agency of Medicines and Health Products (Approval Reference: 2013-A01060-45). Written and signed informed consent was obtained from all patients. The study was registered under the trial identifier NCT03045822. Subjects were eligible if they were over 18 years of age, had CIEDs (PM or ICDs), were not pacing-dependent and did not present acute heart failure. The follow-up period was determined according to the standard control verification of the ICDs and PM at 6 and 12 months, respectively. Patients were excluded if they had a known dysfunction of the implanted device, a particular device lead model prone to developing electronic issues such as the Medtronic Sprint Fidelis (Minneapolis, USA) or the St. Jude Medical Riata leads (St. Paul, USA), and patients implanted less than 2 months ago.

\section{Bioimpedance analysis (BIA) principles}

Principles of BIA have been illustrated by applying the cylinder model to illustrate the relationship between impedance and geometry, an assumption made by considering the shape of the body as five tubes, namely two arms, two legs and a trunk, connected in electrical series. A whole body BIA measurement or the body segment BIA technique can either be performed. Measurement of whole body BIA by applying the hand to foot method is the most frequently used [18]'[19]. This method primarily assesses limb compartments and does not accurately predict the trunk water compartments, which is estimated around $50 \%$ of the body 
mass [20]'[21]'[22]. The segmental BIA allows a better assessment of skeletal muscle mass in comparison to whole body BIA and was introduced to circumvent trunk resistance [7]. In practice, we applied tetrapolar electrodes placed on hands and feet which consist on driving electricity into the body (two current electrodes) and detecting the impedance (two detection electrodes). These measurements are based on considering the body as a cylinder, provide reproducible results and allowed us to established an empirical relationship between the water volume and the square height to resistance ratio $\left(\right.$ height $^{2} / \mathrm{R}$ ) [5]'[23]. In essence, the body reacts to the electrical current by providing two types of resistance: capacitance or reactance arising from the opposition of a condenser such as cell membranes, and resistance from the opposition of a conductor like extra- and intracellular fluid. The impedance is the combination of the two reactance and resistance parameters. All these measurements may vary according to several clinical and biological factors including weight, height, length, age, patient posture, body temperature, intra- and extracellular electrolyte concentration, dehydration and inflammation. In addition, the various tissues of the human body are characterized by different electrical resistance values. For example, adipose tissue and bones are poor electrical conductors (with high impedance), while blood and muscles are better conductors due to their high content in water and electrolytes (with low impedance) [18].

\section{Protocol and Data collection}

Both clinical history and physical examination including device type implant time and programmed device parameters were recorded. Capture and sensing thresholds were assessed in all leads. These diagnostics included impedance trends, oversensing measurements and spontaneous activity recordings (Figure 1). The bioimpedance analysis was performed with the Nutriguard-MS (München, Germany), in which sensing electrodes were placed at the upper limbs and in the opposite side of the device, and impedance measured at 5, 50 and 100 
$102 \mathrm{kHz}$ (Figure 2). All patients were at rest for at least 10 minutes before proceeding with the

103 BIA. The device's battery voltage, leads impedance and pacing thresholds were recorded

104 between each BIA measurement by a cardiac rhythm management specialist. The devices

105 implanted in these patients were from five different manufacturers at the time in France

106 (Biotronik, Boston Scientific, Medtronic, St Jude Medical and Sorin Group).

107 The measuring voltage depends on the R-value of the patient and is totally independently of 108 the battery voltage. At this measurement method, a constant current flow called a "patient 109 helpcurrent" with $0,8 \mathrm{~mA}(=800 \mathrm{uA})$ via the electrodes through the human body. For the 110 measurement that means for patients with $\mathrm{R}<1000 \mathrm{Ohms}$ the measurement current expected 111 is about $U<1$ volt effective.

112 Thus, an output voltage of $1 \mathrm{~V}$ and a power of $1 \mathrm{Vx} 0.8 \mathrm{~mA}=0.8 \mathrm{~mW}$ is applied; and this at all 113 frequencies 5,50, and $100 \mathrm{KHz}$. The output is on average between 0,3-0,8 V, always below $1141 \mathrm{~V}$.

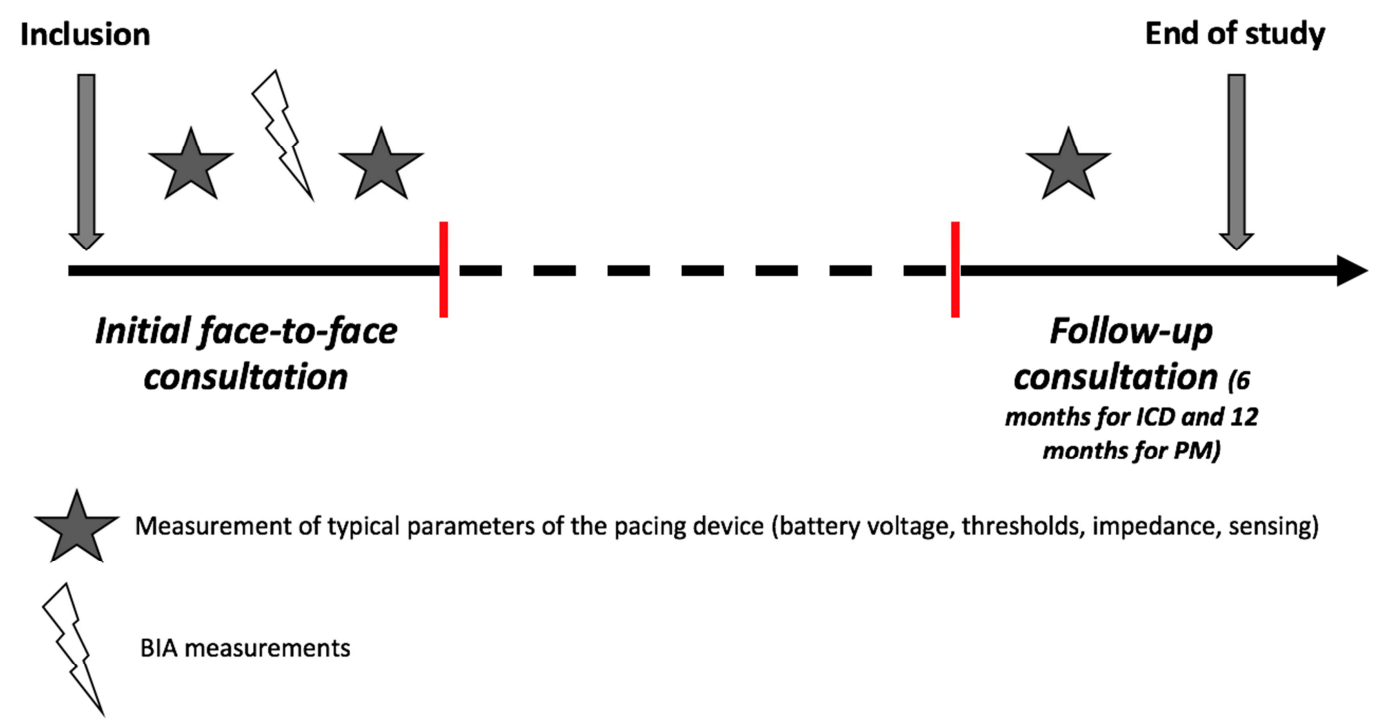

Figure 1: Flow diagram of the study design.

118

119 For PM devices, measurements were performed in both bipolar and unipolar conditions, after 120 which the PM was reset to its initial program. For the entire duration of the BIA, telemetry 
121 was sustained between device and programmer, from which continuous printing of the 122 intracardiac electrograms was collected. The latter were then analyzed for any indication of 123 interference between the Nutriguard-MS (München, Germany) and the PM or ICDs leads and 124 device programmer.

125

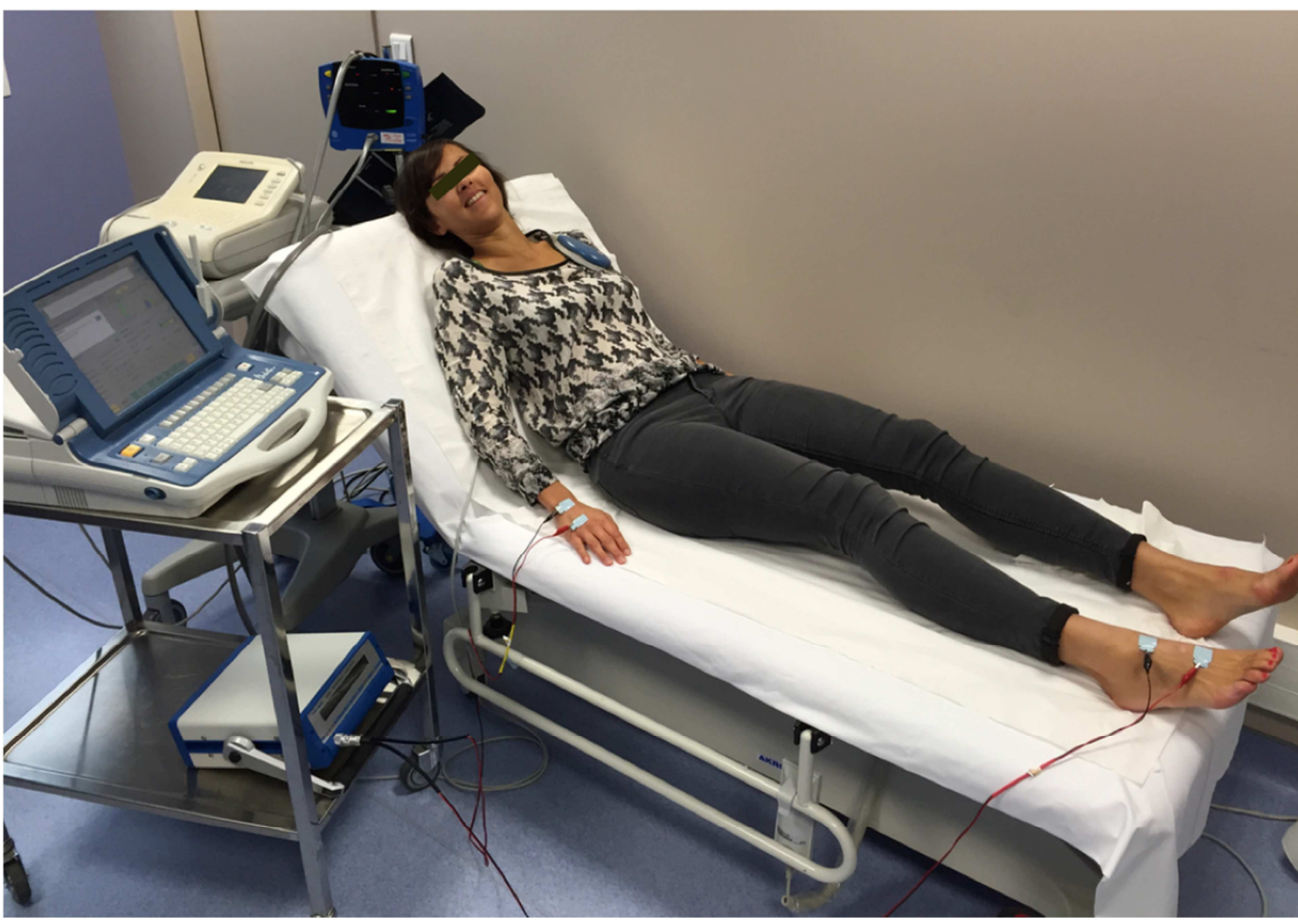

Statistical analysis

130 Sample size was established on the estimation of the incidence of electromagnetic

131 interference between BIA and CIEDs, and its 95\% confidence interval (CI). On the hypothesis

132 that no event will occur, we needed 200 subjects in order to have an upper bound of the $95 \%$

$133 \mathrm{CI}$ at $1.5 \%$ considering Hanley $3 / \mathrm{N}$ formulae. No differences were expected between PM 
134 and ICDs to the BIA application, the reason for which we worked with a single group of 135 patients (100 subjects with PM and 100 with ICDs).

136 The statistical analyses were completed using STATA software, version 12 (Stata Corp, 137 College Station, TX, USA). Categorical variables are expressed as frequency and percentages 138 while quantitative variables are stated as mean values \pm standard deviation (SD, or by median 139 and interquartile range). Normality was checked graphically and performing Shapiro-Wilk's 140 test. In order to evaluate the possible interference of BIA on battery of the device, on lead 141 impedance and pacing thresholds, paired Student t-test was performed (or Wilcoxon matched 142 signed rank test according to data distribution). We performed measurements of the pacing 143 device three times, before and after the BIA application for each patient. We completed theses 144 analyses using generalized linear mixed models, with the subject taken as random effect. 145 Pacing thresholds, lead impedance and battery voltage were considered as the dependent 146 parameters. We tested time and BIA frequency as fixed effects. 
149

150 We enrolled 200 patients with CIEDs in the study between March 2014 and August 2015, comprising 100 subjects with PM and 100 patients with ICDs. Characteristics of patient are reported in Table 1. The majority of subjects implanted with PM were male and the mean age was $79.5 \pm 11.7$ years. For this group of patients, $25 \%$ had single-chamber ventricular pacing,

$15473 \%$ had a dual-chamber and $2 \%$ had a cardiac resynchronization therapy device. In patients 155 with ICDs, the majority were male with an average age of $65.1 \pm 13.3$ years. Single-chamber 156 models were recorded in $57 \%$ of subjects, dual-chamber models in $20 \%$, and a cardiac 157 resynchronization therapy device in $23 \%$ of patients (Table 1). The diagnosis leading to CIED 158 implantation is reported in Table 1. Prior to BIA, all batteries and leads displayed normal 159 function.

160

Table 1: Patient characteristics

\begin{tabular}{|c|c|c|}
\hline Population & $\mathrm{n}(\mathrm{PM})=\mathbf{1 0 0}$ & $\mathrm{n}(\mathrm{ICDs})=\mathbf{1 0 0}$ \\
\hline Age (years) & $79.5 \pm 11.7$ & $65.1 \pm 13.3$ \\
\hline \multicolumn{3}{|l|}{$\operatorname{Sex}(\%)$} \\
\hline Female & 35 & 24 \\
\hline \multicolumn{3}{|l|}{ Number of leads (\%) } \\
\hline Single chamber & 25 & 57 \\
\hline Dual chamber & 73 & 20 \\
\hline Cardiac resynchronization therapy & 2 & 23 \\
\hline \multicolumn{3}{|l|}{ Localization of implantation (\%) } \\
\hline Left & 63 & 95 \\
\hline Years since implantation/replacement & $3.3 \pm 3.6$ & $3.5 \pm 3.2$ \\
\hline \multicolumn{3}{|l|}{ Etiology of implantation (\%) } \\
\hline Atrial Fibrillation (SSS or slow AF) & 25 & \\
\hline Atrioventricular block & 47 & \\
\hline
\end{tabular}




\begin{tabular}{|c|c|c|}
\hline Chronotropic incompetence & 26 & \\
\hline Cardiac resynchronization therapy & 2 & 22 \\
\hline \multicolumn{3}{|l|}{ Primary Prevention } \\
\hline Ischemic cardiomyopathy & & 47 \\
\hline Dilated cardiomyopathy & & 48 \\
\hline \multicolumn{3}{|l|}{ Secondary prevention } \\
\hline Sudden cardiac death & & 9 \\
\hline Ventricular tachycardia & & 28 \\
\hline \multicolumn{3}{|l|}{ Manufacturer (\%) } \\
\hline Biotronik & 15 & 22 \\
\hline Boston Scientific & 6 & 14 \\
\hline Medtronic & 31 & 23 \\
\hline St Jude Medical & 16 & 21 \\
\hline Sorin group & 32 & 20 \\
\hline \multicolumn{3}{|l|}{ Chamber: rate of pacing (\%) } \\
\hline None & 47 & 70 \\
\hline Atrial & 8 & 2 \\
\hline Ventricular & 28 & 15 \\
\hline Both & 17 & 13 \\
\hline
\end{tabular}

(ICDs: implantable cardioverter defibrillators; PM: pacemaker; SSS: sick sinus syndrome)

\section{Evaluation during BIA}

164 During BIA, no changes in the devices' battery voltage, lead impedance or pacing thresholds

165 were detected (Table 2, Figure 3). There were no inappropriate under- or oversensing in far

166 field channels and intracardiac electrograms identified during the continuous telemetry 167 monitoring (i.e. no complete AV block, no pacing inhibition in PM, no oversensing in ICDs 168 leading to inappropriate therapy as anti-tachycardia pacing or shock). No interferences were 
169 detected between the programming and cardiac devices. The different aforementioned device

170 manufacturers were tested and no alterations were observed in the functioning of the

171 implanted device.

172

173 Table 2: Parameters of CIEDs before and after BIA.

174

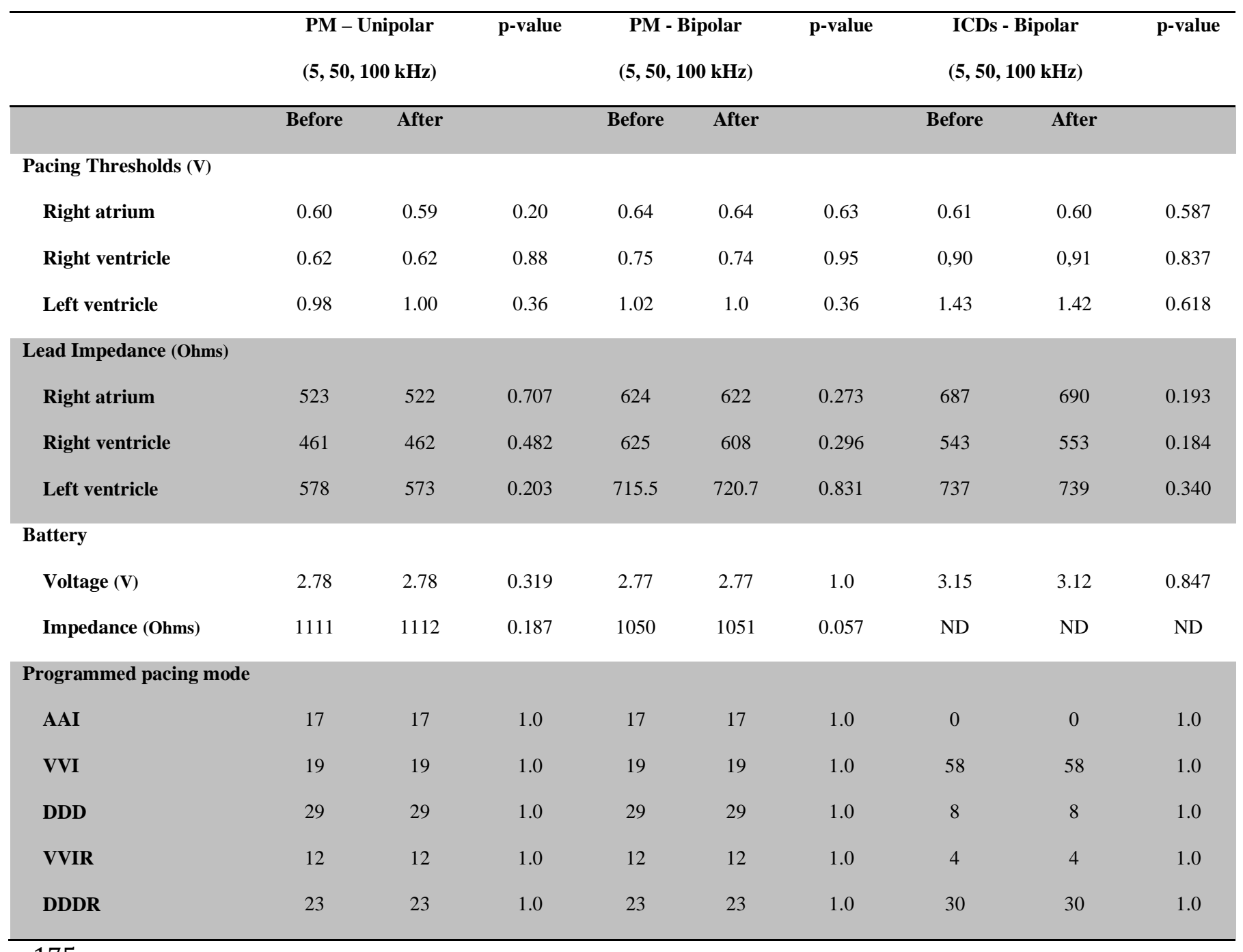

175

176 (CIEDs: cardiac implantable electronic devices; BIA: bioimpedance analysis; V: volt)

177 


\section{Evaluation during 6-12 months follow-up}

179 Out of 100 subjects implanted with PM, 23 patients were lost to follow-up and 65 were 180 examined at 12 months after BIA measurements. Four scheduled replacements (before BIA 181 measurements) were performed prior to the 12-month follow-up visit, one patient had a new 182 implant of a left ventricle lead for cardiac resynchronization, and seven patients were 183 controlled at 2 years instead of at 1 year.

184 Of the 100 patients implanted with ICDs, 8 were lost to follow up and 85 were examined at 6 185 months according to the protocol. Four ICDs were replaced prior to the 6-month visit for 186 scheduled CIED end of life, and three patients were controlled at 12 months.

187 No interaction, including increase in threshold, modification of lead impedance, abnormal 188 decrease in battery voltage, or under-/oversensing, was observed during this follow-up for PM 189 and ICDs.

190

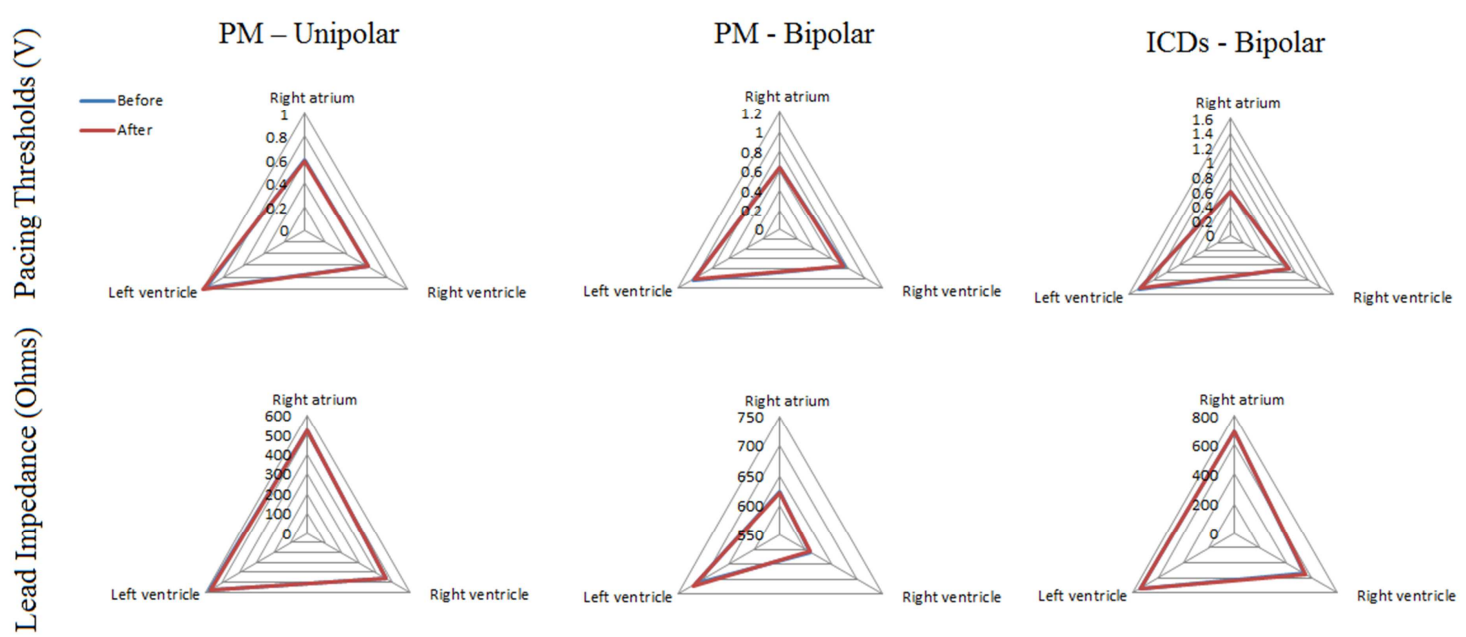




\section{DISCUSSION}

195 Manufacturers and clinical practice guidelines do not recommend whole body BIA in patients

196 with cardiac implantable electronic devices because of possible electromagnetic interferences,

197 although literature data regarding its safety is rarely encountered. Hence, BIA has not been

198 widely used to date in this group of patients, regardless of its non-invasive nature. The present

199 work demonstrates the absence of alterations in the functioning of CIEDs (PM and ICDs)

200 during the use of BIA. In our cohort of 200 patients with CIEDs, we did not detect any signal

201 over-, undersensing or pacing inhibition, as well as no changes in device battery voltage, lead

202 impedance and pacing thresholds, thus suggesting the safety of using BIA in this specific

203 population. As a result, patients with PM or ICD are not at risk of putative complications

204 under BIA.

205 A consequence of the electrical current is over-sensing which can induce resistance-wave 206 oversensing leading to inhibition of ventricular pacing in pacing-dependent patients, and/or 207 inappropriate shock in patients with ICD devices and alterations in the device programmer.

208 All devices are programmed based on the endogenous heart rates and to detect cardiac signals 209 between 10 to $70 \mathrm{~Hz}$ [24]. Consequently, all signals outside of these ranges are not captured 210 by cardiac devices. For BIA assessments herein, the conductance of the electrical current was 211 measured at three frequencies, namely 5, 50 and $100 \mathrm{kHz}$, a range outside the detected field 212 by CIEDs.

213 There is some reported evidence of electromagnetic interference between cardiac pacemakers 214 and cellular telephones/media players, preventing the PM from functioning properly and 215 causing inhibition of pacing or resulting in painful inappropriate shocks [25]' [26]. Others 216 have identified electromagnetic interference between digital music players and PM/CDs, 217 however with no effect on intrinsic device function [27]. 
218 Recent studies have shown the safety of using bioimpedance vector analysis (BIVA) in

219 patients with CIEDs. BIVA is another method for interpreting bioimpedance information by

220 plotting impedance as a bivariate vector based on its resistance (on the $\mathrm{X}$ axis) and capacitive

221 reactance (on the $\mathrm{Y}$ axis) components. In a study by Buch et al. evaluating a cohort of 20

222 subjects with chronic heart failure and implanted ICDs, the authors did not observe any

223 effects of BIVA on intracardiac electrograms or surface electrocardiograms from any lead,

224 whether atrial or ventricular, in patients with cardiac resynchronization therapy [28]. In

225 addition, no inappropriate sensing in device marker channels as well as no telemetric

226 interference was observed between BIVA and the CIEDs. Another study conducted in 21

227 patients with acute heart failure decompensation showed no changes with regard to device

228 function and leads, or alterations in wire parameters or inappropriate sensing in channels

229 during BIVA [29].

230 In a recent study, 63 patients implanted with various single-chamber, dual-chamber and

231 biventricular ICDs from different manufacturers underwent BIA measurements in

232 concomitance with routine ICD controls [30]. The study revealed no electromagnetic

233 interferences or artifacts during real-time electrocardiogram recordings using an electrical

234 current of $0.8 \mathrm{~m}$ Amp at frequencies from 5-100 kHz.

235 The above-mentioned studies are however limited to small sample sizes, no long-term follow-

236 up and/or to a restricted brand of cardiac devices. In addition, patients implanted with PM

237 have been analyzed in only one study where the authors investigated the function of only 13

238 PM devices.

239 In the present study involving a large number of enrolled subjects with PM and ICDs, we

240 performed BIA and analyzed for any occurrence of electromagnetic interference. Indeed, as

241 previous studies, our results showed no effect on device function or lead parameters. To our 
242 knowledge, this data shows for the first time the long term safety of using BIA in a larger 243 cohort of patients with CIEDs.

244 There are several reasons to perform BIA in patients with chronic heart failure. In this 245 population, overweight and obese subjects are at lower risk of death than patients with 246 normal body weight, suggesting an association between higher body mass index (BMI) levels 247 and survival [31]. Also, BIA can be used to facilitate the earlier recognition of cachexia, a 248 poor prognostic sign, in chronic heart failure patients [32]. Furthermore, it has been shown 249 that involuntary weight loss and malnutrition continue to be prevalent among hospitalized 250 patients [33]. Therefore, the outcome of BIA measurements such as the resistance and 251 reactance is of interest to determine nutritional risk and to be predictive for prognosis in 252 various diseases [34]'[35].

253 The BIA method has also been validated for quantifying the amount of fluid retention and 254 accumulation in acute decompensated heart failure patients and to provide a useful support for 255 the management of these subjects especially those hospitalized in an acute care unit [36]. 256 Moreover, BIA has been accurately used for diagnosis and guidance of treatment in acute 257 decompensated heart failure patients [37]. Hence, the current guideline against using BIA in 258 patients with PM and ICDs will ultimately exclude a considerable percentage of these patients 259 with chronic heart failure from this valuable analysis.

\section{Study limitations}

262 Despite the advantages of the BIA method and its ability to be used in a population of patients 263 with PM and CDs, it should not be performed on subjects with extremely low $(<25 \mathrm{~kg})$ or 264 high (>220 kg) body weight. Secondly, the measurements using the Nutriguard-MS herein 265 were made with frequencies from 5 to $100 \mathrm{kHz}$. It is not excluded that other BIA systems 266 using different frequencies (up to $500 \mathrm{kHz}$ ) may interfere with the CIEDs. Although pacing- 
267 dependent patients have not been included (due to ethical considerations) in the present 268 analysis, our results as well as previous reported data discussed above are in agreement with 269 recommending BIA in all CIEDs patients regardless of pacing-dependent status.

270

\section{CONCLUSION}

272 BIA could provide a useful insight in patients implanted with PM and ICDs. The present 273 findings show that the use of BIA in this group of patients is safe and is without risk with 274 regard to the function of these CIEDs. Current recommendations cited by manufacturers and 275 guidelines by international societies should be reviewed and adapted accordingly.

276

277 ACKNOWLEDGMENTs: We thank Mr. Pierre Pothier for the editing of this manuscript.

278 Statement FOR AUTORSHIP: XC, BP, FJ, RE have participated to the preparation of the

279 design of the study. All authors have materially participated in the article preparation (XC, 280 OL, AM, PB, FJ, EF, GM, MA, GS, SP, YB, RR, BC, JRL, TG, BP, PM, GC, RE).

281 All authors have approved the final article.

CONFLICTS OF INTEREST: None

FUNDING SOURCES: None 


\section{REFERENCES}

[1] Tagney J. A literature review comparing the experiences and emergent needs of adult patients with permanent pacemakers (PPMs) and implantable cardioverter defibrillators (ICDs). J Clin Nurs 2010;19:2081-9. doi:10.1111/j.1365-2702.2009.03031.x.

[2] Mond HG, Proclemer A. The 11th world survey of cardiac pacing and implantable cardioverter-defibrillators: calendar year 2009--a World Society of Arrhythmia's project. Pacing Clin Electrophysiol PACE 2011;34:1013-27. doi:10.1111/j.15408159.2011.03150.x.

[3] Kalin R, Stanton MS. Current clinical issues for MRI scanning of pacemaker and defibrillator patients. Pacing Clin Electrophysiol PACE 2005;28:326-8. doi:10.1111/j.1540-8159.2005.50024.x.

[4] Cheng A, Nazarian S, Spragg DD, Bilchick K, Tandri H, Mark L, et al. Effects of surgical and endoscopic electrocautery on modern-day permanent pacemaker and implantable cardioverter-defibrillator systems. Pacing Clin Electrophysiol PACE 2008;31:344-50. doi:10.1111/j.1540-8159.2008.00996.x.

[5] Kyle UG, Bosaeus I, De Lorenzo AD, Deurenberg P, Elia M, Gómez JM, et al. Bioelectrical impedance analysis--part I: review of principles and methods. Clin Nutr Edinb Scotl 2004;23:1226-43. doi:10.1016/j.clnu.2004.06.004.

[6] Kyle UG, Bosaeus I, De Lorenzo AD, Deurenberg P, Elia M, Manuel Gómez J, et al. Bioelectrical impedance analysis-part II: utilization in clinical practice. Clin Nutr Edinb Scotl 2004;23:1430-53. doi:10.1016/j.clnu.2004.09.012.

[7] Mika C, Herpertz-Dahlmann B, Heer M, Holtkamp K. Improvement of nutritional status as assessed by multifrequency BIA during 15 weeks of refeeding in adolescent girls with anorexia nervosa. J Nutr 2004;134:3026-30.

[8] Utter AC, Nieman DC, Mulford GJ, Tobin R, Schumm S, McInnis T, et al. Evaluation of leg-to-leg BIA in assessing body composition of high-school wrestlers. Med Sci Sports Exerc 2005;37:1395-400.

[9] Zhu F, Kuhlmann MK, Kotanko P, Seibert E, Leonard EF, Levin NW. A method for the estimation of hydration state during hemodialysis using a calf bioimpedance technique. Physiol Meas 2008;29:S503-516. doi:10.1088/0967-3334/29/6/S42.

[10] Kyle UG, Genton L, Pichard C. Low phase angle determined by bioelectrical impedance analysis is associated with malnutrition and nutritional risk at hospital admission. Clin Nutr Edinb Scotl 2013;32:294-9. doi:10.1016/j.clnu.2012.08.001.

[11] Toso S, Piccoli A, Gusella M, Menon D, Bononi A, Crepaldi G, et al. Altered tissue electric properties in lung cancer patients as detected by bioelectric impedance vector analysis. Nutr Burbank Los Angel Cty Calif 2000;16:120-4.

[12] Zlochiver S, Arad M, Radai MM, Barak-Shinar D, Krief H, Engelman T, et al. A portable bio-impedance system for monitoring lung resistivity. Med Eng Phys 2007;29:93-100. doi:10.1016/j.medengphy.2006.02.005.

[13] Cox-Reijven PLM, van Kreel B, Soeters PB. Bioelectrical impedance measurements in patients with gastrointestinal disease: validation of the spectrum approach and a comparison of different methods for screening for nutritional depletion. Am J Clin Nutr 2003;78:1111-9.

[14] Massari F, Iacoviello M, Scicchitano P, Mastropasqua F, Guida P, Riccioni G, et al. Accuracy of bioimpedance vector analysis and brain natriuretic peptide in detection of peripheral edema in acute and chronic heart failure. Heart Lung J Crit Care 2016;45:319-26. doi:10.1016/j.hrtlng.2016.03.008.

[15] Siedlecka J, Siedlecki P, Bortkiewicz A. Impedance cardiography - Old method, new opportunities. Part I. Clinical applications. Int J Occup Med Environ Health 2015;28:2733. doi:10.13075/ijomeh.1896.00451. 
[16] Bracco D, Revelly JP, Berger MM, Chioléro RL. Bedside determination of fluid accumulation after cardiac surgery using segmental bioelectrical impedance. Crit Care Med 1998;26:1065-70.

[17] Xiajuan Z, Ding D, Yanyan H, Zhen H. Impedance cardiographic hemodynamic variables and hypertension in elderly Han residents. Ups J Med Sci 2013;118:80-6. doi:10.3109/03009734.2012.756959.

[18] Lukaski HC, Bolonchuk WW, Hall CB, Siders WA. Validation of tetrapolar bioelectrical impedance method to assess human body composition. J Appl Physiol Bethesda Md 1985 1986;60:1327-32.

[19] Buchholz AC, Bartok C, Schoeller DA. The validity of bioelectrical impedance models in clinical populations. Nutr Clin Pract Off Publ Am Soc Parenter Enter Nutr 2004;19:433-46.

[20] Kyle UG, Genton L, Karsegard L, Slosman DO, Pichard C. Single prediction equation for bioelectrical impedance analysis in adults aged 20--94 years. Nutr Burbank Los Angel Cty Calif 2001;17:248-53.

[21] Foster KR, Lukaski HC. Whole-body impedance--what does it measure? Am J Clin Nutr 1996;64:388S-396S.

[22] Earthman C, Traughber D, Dobratz J, Howell W. Bioimpedance spectroscopy for clinical assessment of fluid distribution and body cell mass. Nutr Clin Pract Off Publ Am Soc Parenter Enter Nutr 2007;22:389-405.

[23] Khalil SF, Mohktar MS, Ibrahim F. The theory and fundamentals of bioimpedance analysis in clinical status monitoring and diagnosis of diseases. Sensors 2014;14:10895928. doi:10.3390/s140610895.

[24] Summers RL, Shoemaker WC, Peacock WF, Ander DS, Coleman TG. Bench to bedside: electrophysiologic and clinical principles of noninvasive hemodynamic monitoring using impedance cardiography. Acad Emerg Med Off J Soc Acad Emerg Med 2003;10:669_ 80.

[25] Hayes DL, Wang PJ, Reynolds DW, Estes M, Griffith JL, Steffens RA, et al. Interference with cardiac pacemakers by cellular telephones. N Engl J Med 1997;336:1473-9. doi:10.1056/NEJM199705223362101.

[26] Thaker JP, Patel MB, Jongnarangsin K, Liepa VV, Thakur RK. Electromagnetic interference with pacemakers caused by portable media players. Heart Rhythm Off J Heart Rhythm Soc 2008;5:538-44. doi:10.1016/j.hrthm.2008.01.028.

[27] Webster G, Jordao L, Martuscello M, Mahajan T, Alexander ME, Cecchin F, et al. Digital music players cause interference with interrogation telemetry for pacemakers and implantable cardioverter-defibrillators without affecting device function. Heart Rhythm Off J Heart Rhythm Soc 2008;5:545-50. doi:10.1016/j.hrthm.2008.02.033.

[28] Buch E, Bradfield J, Larson T, Horwich T. Effect of Bioimpedance Body Composition Analysis on Function of Implanted Cardiac Devices. Pacing Clin Electrophysiol 2012;35:681-4. doi:10.1111/j.1540-8159.2012.03377.x.

[29] Fabregat-Andrés Ó, Fácila L, Montagud-Balaguer V, Galán-Serrano A. Systemic bioimpedance analysis in patients with implanted cardiac stimulation devices. Nefrol Publicacion Of Soc Espanola Nefrol 2015;35:345-6. doi:10.1016/j.nefro.2014.12.002.

[30] Meyer P, Makhlouf A-M, Mondouagne Engkolo LP, Trentaz F, Thibault R, Pichard C, et al. Safety of Bioelectrical Impedance Analysis in Patients Equipped With Implantable Cardioverter Defibrillators. JPEN J Parenter Enteral Nutr 2016. doi:10.1177/0148607116633823.

[31] Oreopoulos A, Padwal R, Kalantar-Zadeh K, Fonarow GC, Norris CM, McAlister FA. Body mass index and mortality in heart failure: a meta-analysis. Am Heart J 2008;156:13-22. doi:10.1016/j.ahj.2008.02.014. 
[32] Evans WJ, Morley JE, Argilés J, Bales C, Baracos V, Guttridge D, et al. Cachexia: a new definition. Clin Nutr Edinb Scotl 2008;27:793-9. doi:10.1016/j.clnu.2008.06.013.

[33] Pablo AMR, Izaga MA, Alday LA. Assessment of nutritional status on hospital admission: nutritional scores. Eur J Clin Nutr 2003;57:824-31. doi:10.1038/sj.ejen.1601616.

[34] Norman K, Stobäus N, Pirlich M, Bosy-Westphal A. Bioelectrical phase angle and impedance vector analysis--clinical relevance and applicability of impedance parameters. Clin Nutr Edinb Scotl 2012;31:854-61. doi:10.1016/j.clnu.2012.05.008.

[35] Reis de Lima e Silva R, Porto Sabino Pinho C, Galvão Rodrigues I, Gildo de Moura Monteiro Júnior J. [Phase angle as an indicator of nutritional status and prognosis in critically ill patients]. Nutr Hosp 2014;31:1278-85. doi:10.3305/nh.2015.31.3.8014.

[36] Sakaguchi T, Yasumura K, Nishida H, Inoue H, Furukawa T, Shinouchi K, et al. Quantitative Assessment of Fluid Accumulation Using Bioelectrical Impedance Analysis in Patients With Acute Decompensated Heart Failure. Circ J Off J Jpn Circ Soc 2015;79:2616-22. doi:10.1253/circj.CJ-15-0723.

[37] Gil Martínez P, Mesado Martínez D, Curbelo García J, Cadiñanos Loidi J. Aminoterminal pro-B-type natriuretic peptide, inferior vena cava ultrasound, and biolectrical impedance analysis for the diagnosis of acute decompensated CHF. Am J Emerg Med 2016;34:1817-22. doi:10.1016/j.ajem.2016.06.043. 


\section{FigURES LEGENDS}

\section{Figure 1: Flow diagram of the study design.}

The study included two groups of participants, one group with implantable cardioverterdefibrillators (ICDs) and a group with pacemakers (PM). The follow-up visits were at 6 and 12 months, respectively.

\section{Figure 2: Patient installation.}

Bioimpedance analysis (BIA) was performed with the Nutriguard-MS (München, Germany), in which sensing electrodes are placed at the upper limbs and on the opposite side of the device, with impedance measurements performed at 5, 50 and $100 \mathrm{kHz}$. All patients were at rest for at least 10 minutes prior to proceeding with BIA.

\section{Figure 3: Evolution of devices parameters before and after BIA.}

No differences in unipolar and bipolar measurements were observed in PM and ICDs concerning leads impedance and pacing thresholds, before and after BIA. 